\title{
Aerobiological studies - current state and future challenges
}

\section{Dorota Myszkowska}

Jagiellonian University Medical College, Department of Clinical and Environmental Allergology, Head of Allergological-Immunological Laboratory

Coordinator of the Polish Aerobiological Network President of the International Association for Aerobiology Jagiellonian University Medical College, Department of Clinical and Environmental Allergology Head: prof. Ewa Czarnobilska, MD, PhD

\begin{abstract}
:
Aerobiology is the interdisciplinary science focused on the study of airborne organisms and biological materials, like pollen grains, fungal spores, bacteria, viruses, mycotoxins. The results of the aerobiological monitoring are practically employed in medicine, agriculture, beekeeping, meteorology, monument protection. The information of the current and predicted exposure is transmitted to patients and physicians through the electronic tools, applications, media, to compile the optimal therapy of respiratory diseases, especially pollen allergy. It is worth taking into account some confirmed phenomena to interpret the aerobiological data correctly: (i) many airborne particles occur seasonally and their amount and seasonal dynamics are more or less variable; (ii) threshold values for the airborne particles causing the threat for humans (e.g. for allergic individuals) are important, but the personal sensitivity must be also included; (iii) overlapping occurrence of different airborne particles, like pollen, spores, pollution makes clinical symptoms worsening; (iv) modern pollen and spores fall is affected in direct and indirect way by the climate changes, anthropogenic pollution, long range transport and the specific local environmental conditions. Currently the implementation of the automatic measurement systems and the analyses of allergen particles in the air are the main challenges for aerobiologists. Joined activity of this group of enthusiastic specialists of different interests is performed in frame of the multi centre networks and supported by the International Association for Aerobiology together with the regional.
\end{abstract}

Key words: aerobiology, volumetric monitoring, pollen and fungal spores, automatic samplers

\section{Introduction}

Aerobiology is a scientific discipline, that deals with the passive transport of organisms and particles of organic origin in the air, including their release into the atmosphere, spreading, deposition and impact on other living organisms. This term was used, for the first time, by Fred C. Meier in 1930, then was mentioned in 1964 in the introduction into the International Biological Programme (IBP), focused on the productivity of world ecosystems. In 1974 the International Aerobiology Association (IAA) was established during the First International Congress of Ecology in Hague and henceforth organization and international outlook of aerobiology as a new science branch was considered as really new phenomenon (https://iaaerobiology.wordpress.com, access: March 20 $\left.0^{\text {th }}, 2020\right)$ [1, 2].

The wide range of observations, including: aetiology of various diseases caused by plant pollen allergens, fungal spores, bacteria, viruses, mycotoxins, faecal pellets from mites, urinary proteins from laboratory and farm animals and organic particles from industrial processes; the mechanisms of the spread of organic particles in the air and studies on the phenomena of wind-pollination contributed to the development of this discipline [3]. 
Aerobiology as the interdisciplinary science is closely associated with ecology, botany, phenology, palynology, mycology, microbiology, meteorology, climatology, as well as chemistry and physics of the atmosphere. Many scientific problems are solved on the border of the different fields of science, which completes each other and aerobiology. The visible development of the aerobiological analyses occurred in the last century, and particularly concerned aeropalynological observations of plant pollen and fungal spores in the air.

Monitoring of the modern pollen and spores fall is based on the methods applied for the reconstruction of the plant and climate history, especially Holocene and Pleistocene deposits. Nowadays, it is practically employed in medicine (allergology, forensic medicine, occupational medicine), agriculture (crop forecasting), beekeeping (determination of plant pollen in honey, forecasting harvests), meteorology (climate change assessment), monument protection (measurements of fungal spore concentrations in museum buildings).

\section{Some aspects of aerobiological studies worth knowing}

An interest in aerobiology is probably the most noticeable in the field of allergology, due to the intensive increase in the incidences of pollen allergy (AR, allergic rhinitis) since the 1930s [4]. English physician Charles H. Blackley is regarded as one of the fathers of the modern aerobiology, when in 1873, pointed out that pollen occurring in large quantities in summer causes the breathing problems (called catarrhus aestivus or summer catarrh) [5].

Over 150 years later, pollen reports are commonly used in the medical every day practice. Measurements of plant pollen and fungal spores as carriers of allergens are helpful for the diagnosis of AR, monitoring of symptomatic treatment and specific immunotherapy and for the estimation of the effectiveness of treatment, as well as for the prevention of AR. As it was stressed by Obtułowicz et al. [6], the efficacy of drug treatment in patients with pollen allergy during the pollen season assessed by using conventional symptom scores may be incorrect in about one third of cases, if changes in the pollen concentration are not taken into account.

Nowadays, the information of the pollen threat is implemented into the different therapeutic systems, like MASK-rhinitis (MACVIA-ARIA Sentinel NetworK for allergic rhinitis), which is a simple system based on the most widely used guideline in allergic rhinitis and its asthma comorbidity. Three tools were im- plemented for this electronic monitoring: daily visual analogue scale (VAS), CARAT (Control of Allergic Rhinitis and Asthma Test) and e-Allergy screening. The important part of the system is MASK-aerobiology collecting pollen data at the onset of the pollen season and thereafter every 2 weeks to transmit the information to patients and to the media with regard to the pollen season, to compile the optimal therapy for the patients with allergic symptoms, clinical trials, research and climate evaluation [7].

The hot problem being still unsolved definitely is the estimation of threshold values of pollen concentrations causing a threat for sensitive individuals. The results of the Task Force of the Immunotherapy and Aerobiology and Pollution Interest Groups of the EAACI published in 2017 [8] presented a comprehensive position in defining pollen exposure times for the most important European allergenic pollen (of birches, grasses, olive trees and ragweed). Definitions of "pollen season", "high pollen season" (or "peak pollen period") and "high pollen days", were proposed for analysis of outcomes in allergen immunotherapy in allergic rhinoconjunctivitis due to pollen. It was also highlighted, that allergy sufferers may "expect" symptoms at the beginning of the announced season as "anticipation effect".

The growing knowledge of the pollen and fungal seasons dynamics and their annual variability depend on the plants behaviour, especially in relation to the season beginning and its intensity [9-11], which let us to develop the more and more effective predicting models for the seasons onset and pollen amount [12, 13]. To be up-to-date with the current and forecasted pollen information, the visualizations based on aerobiological, phenological, meteorological data are presented, e.g. an open-code system SILAM arranged by the Finnish Meteorological Institute (http://silam.fmi. fi, access: March 25 ${ }^{\text {th }}, 2020$ ). The forecasts contain the pollen concentrations of the selected allergenic species over Europe with a $10 \mathrm{~km}$ spatial resolution and 1 hour time step, including alder, birch, grass, olive, and ragweed pollen.

The other well-known problem is the individual patients sensitivity to pollen allergens regarding the dose of the pollen exposure and the exact risk time. As widely suggested the inclusion of personal symptoms will lead to major improvements in pollen information concerning hay fever sufferers [14]. To compare the patients allergic with the concentrations of pollen in the air, the personal application Patient's hayfever diary was proposed by the European Pollen Service (https:// www.polleninfo.org). Data saved by users let to visualise the current map of symptoms (Symptom load map) 
from and for allergy sufferers, and to produce the specific maps of monthly pollen load of different plants on the basis of the past 10-15 years (fig. 1). report informs on a higher percentage of people with pollen allergy in urban areas, than in areas with a low level of the abiotic pollution [17-20]. Pollution trans-

Figure 1. European pollen map of birch (Betula pendula) in April (Code: white nil, green low, yellow moderate, orange high and red very high) (https://www.pollenwarndienst.at/AT/en/current-data/pollen-load-map-of-europe. html? iframe $=0$, access: March 26 $6^{\text {th }}$, 2020).

Image courtesy of EAN (European Aeroallergen Network) Medical University Vienna, Austria.

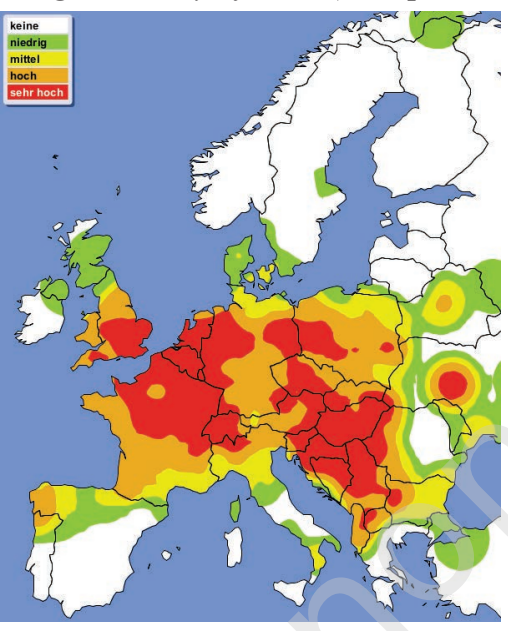

1.-10. April

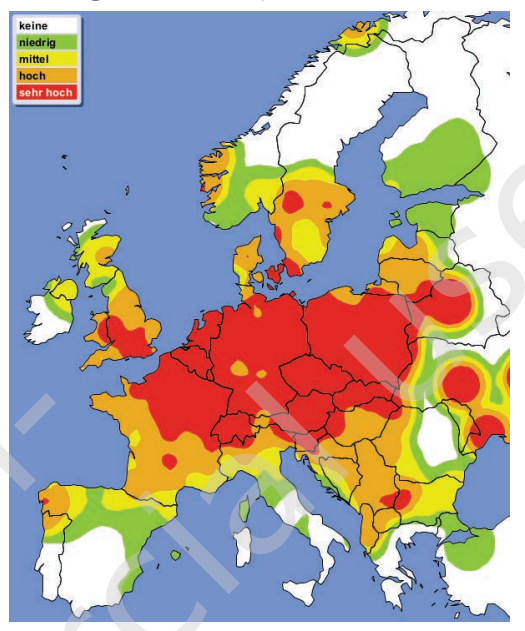

11.-20. April

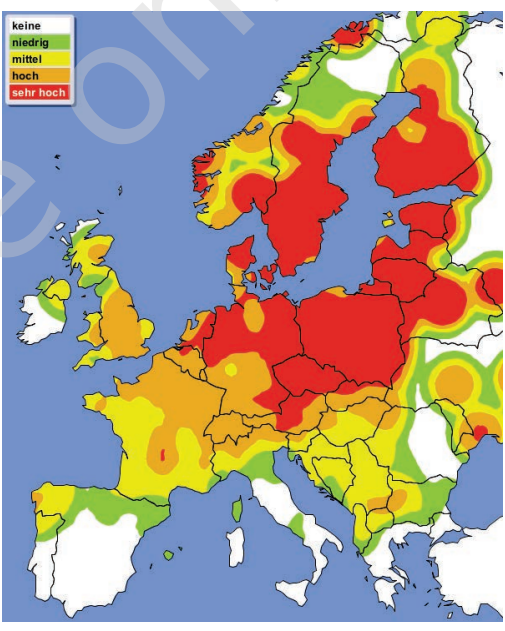

21.-30. April
In the last several years, the problem of cross-reactivity between pollen and food allergens has been more and more frequently diagnosed in the patients with pollen allergy. In the Global atlas of allergic rhinitis and rhinosinusitis [15] it was clearly emphasized, that the observed cross-reactivity between pollen and plant food causing OAS can be correlated with sensitization to a small number of well-known allergens, the patients sensitization profile follows the geographical distribution and that occasionally, OAS may be the first symptom of other food allergy manifestations (cutaneous, digestives, respiratory), even anaphylaxis. Patients are advised to avoid fresh cross-reacting food, first of all the raw fruits and vegetables, especially during the pollen season. For these reasons, the new challenge for aerobiologists is to spread the information of the cross-reacting pollen in the regular reports in frame of the prophylaxis of pollen allergy.

Overlapping contamination of allergenic pollen and pollution is the next common topic for aerobiologists and physicians. This phenomenon was recognized and described in the 90ties of the last century as the main factor responsible for the increase in pollen allergy up to $30 \%$ of population in Europe [16]. Considering, that the problem of the atmospheric pollution concerns up to $96 \%$ of the European Union urban population, according to the latest European Environment Agency report [17] (http://www.eea.europa.eu, access: March $\left.15^{\text {th }}, 2020\right)$, it is not surprising that the ported on the surface of pollen grains can modify its morphological sculpture and molecular structure of proteins [21, 22], straighten their immunoreactivity and facilitating allergens penetration through the mucous membrane. It is suggested to measure pollen allergenicity, as a risk parameter, for assessment of air emissions and climate changes [23, 24]. Meeting the challenges of the modern world and knowing changes in our environment, we can see a need to change local and regional pollen calendars and predictive models, adding the information on the pollution level. In addition, the knowledge of phenomena such as: extension of pollen seasons, increase in protein allergenicity, changes in the pollen protein profile should be taken into account when assessing the effectiveness of the pollen allergy therapy and when planning prevention methods for patients.

It is confirmed, that the "greenhouse effect" closely related to the increase in $\mathrm{CO}_{2}$ concentration, as a result of anthropogenic pollution, affects the plants biomass production, including pollen of allergenic potency, e.g. Ambrosia artemisiifolia produces $61-90 \%$ more pollen when $\mathrm{CO}_{2}$ concentration is high, which is associated with the previous growing season [25]. Alarming forecasts for the future (up to 2070) on the spread of $A$. artemisiifolia in Europe published in 2014, predict a northward shift in the available climatic niche for ragweed populations to establish and persist risk of increased health problems in the northern countries 
including the UK and Denmark. This was accompanied by an increase in the relative pollen production at the northern edge of its range, while the southern European limit was not expected to change [26].

Observations of "modern" pollen fall play an important role in assessing climate changes. The study carried out in 17 representative pollen monitoring centres in the Northern Hemisphere (over a 20 year observation), showed a substantial increase in pollen concentration of allergenic plants in most of the analyzed regions and a pollen seasons elongation by an average of 0,9 days/year. Cumulative daily maximum $\left(\mathrm{T}_{\max }\right)$ and minimum $\left(\mathrm{T}_{\min }\right)$ temperature were considered as main factors responsible for these changes, in relation to the "greenhouse effect" [27].

In 2012, in „Plos One” the specific results of the pollen seasons variability in Europe were published, based on a multi-station analysis (1221 pollen time series, in 10-28 years, at 97 locations in 13 European countries for 23 taxa pollen). Temporal trends of API (Annual Pollen Index) indicated a clear tendency towards an increase in atmospheric pollen, including highly allergenic taxa. These trends could not be attributed to rising temperature, but they may be influenced by the anthropogenic increase in the greenhouse gas $\mathrm{CO}_{2}[28]$.

The longer and more intensive the pollen seasons are, the expended exposure to pollen allergens and the increase in clinical symptoms in the sensitive individuals. Pollen and fungal spore seasons often overlap, making a potential risk of the intensified exposure, as in the case of ragweed (Ambrosia) and mugwort (Artemisia) pollen in Poland. The mugwort pollen seasons most often begin in the second half of July, while ragweed pollen season starts are much more variable from year to year, starting the most often in the second decade of August. Considering the full Artemisia pollen season as $100 \%$, the co-occurrence of the days with Ambrosia pollen grains $\geq 10 \mathrm{PG} / \mathrm{m}^{3}$ ranges from $5 \%$ to $14 \%$, when the higher threat for sensitive people is expected [29].

The problem of the long range pollen transport is closely related to the pollen occurrence in unexpected time or to intensity of the symptoms. The most spectacular and widely described is phenomenon of LRT in case of Ambrosia (ragweed) pollen, less common, but also reported refers to birch, Pinaceae or alder pollen. The evaluation of the Ambrosia pollen long transport even to the northern part of Europe indicated the possible pollen arrival from the Pannonian Plain, under the suitable synoptic conditions required for the pollen air masses moving northward [30, 31].
The analysis of biological material for the needs of: forensics, the fight against bioterrorism, or the risk assessment of biodegradation of historic buildings is a reason for aerobiologists to continue their research. Aerobiology studies are a useful tool to safeguard of public health, especially to improve prevention, diagnosis and clinical management of respiratory track diseases, caused by airborne contaminants. For these wide-ranging purposes, both the advanced methods, like next-generation sequencing (NGS) [32] and traditional microbiological [33] procedures are used, to evaluate the indoor air quality in occupational and public health settings. The measurement of biological particles contamination is performed for specific purposes or in the untypical places. Pollen, fungal spores together with bacteria have been monitored quarterly in the Wieliczka Salt Mine (southern Poland) in last eight years [34]. The concentration of fungal spores and bacteria in the underground environment differs among the seasons, while the presence of pollen in salt chambers is definitely lower than on the surface which indicates the biological material delivered to the chambers by patients and staff. The indoor bioaerosol content seems to be typical for public facilities and is more stable than that in the outdoor air [34].

\section{Future challenges for aerobiologists}

\section{Real-time monitoring}

A mile stone in the sampling methods has been introduction of the automatic devices to the volumetric measurements. Commonly used the Hirst type samplers are recommended for the routine sampling procedures, but they are time consuming and they limit us to reports on the basis of data collected in the previous week [35]. For forecasting purposes, a continuous, real-time monitoring would be more valuable. For this reason, the automatic methods have been developed and implemented to the measurement of pollen and fungal spores of selected taxa.

Currently, two methods of particles detection seem to be the most suitable for taxon-level classification of pollen: based on image recognition and laser fluorescence (or their combinations). Image-based technologies are used in detectors, such as BAA500 (Helmut Hund GmbH, https://www.hund.de, access: March $26^{\text {th }}$, 2020); the laser-fluorescence-based approach is implemented in a wideband integrated bioaerosol sensor (WIBS) device (http://www.dropletmeasurement.com, access: March 26 $\left.{ }^{\text {th }}, 2020\right)$, PA-300 and Rapid-E (Plair, http://www.Plair.ch, access: March $\left.26^{\text {th }}, 2020\right)$, whereas 
the new Poleno device (Swisens, https://swisens.ch, access: March $26^{\text {th }}, 2020$ ) aims at integration of both features [36-38]. Until now, the large-scale evaluation and calibration of the samplers before the routine application, suitable for European-scale have yet to be concluded. A stream of data detected in short time intervals needs to be validated, before any reports for patients are spread. However, the early warning, preventive medication, operative decision made, are the advantages of new solutions, that are worth to be improved. This activity is led by Autopollen program, as one of the tasks of EuMetNet Platform. To the main objectives belong: definition of the main standards of automatic pollen monitoring (methods, sites, data format, quality assessment and control, etc.) and demonstration of the feasibility of a European network by integration of the current and planned projects (https://www.eumetnet.eu, access: March 29'th 2020 ).

\section{Allergens detection in the air}

Pollen grains are treated as the carriers of allergens, which in favourable conditions (mucous membrane, rain drops) or after the pollen cracking are released outside. Tiny allergen particles $(<2 \mu \mathrm{m}$ in diameter) are found in the respirable fraction PM 2,5 of the air using special samplers, e.g. the high-volume cascade impactor and those particle concentrations are determined by enzyme immunoassay (ELISA). In frame of the HIALINE project (European Union Project Health Impacts of Airborne Allergen Information Network), it was found that Phl p 5, the main Phleum pratense protein was released in amount from less than 1 to 9 pg of Phl p 5 per pollen (potency). Allergens content varies among locations in Europe and during the pollen season [39]. The results of the study performed in Poznań (northwestern Poland) showed that daily Art v 1 levels correlated significantly with mean daily concentrations of Artemisia pollen, depending on the air fraction and peak of the season. The authors stressed, that during the mugwort pollen season, several Artemisia species are responsible for pollen potency, not only the most common A. vulgaris [40].

\section{Reaching higher}

Scientists in the Aerobiology Lab at NASA Ames Research Center, in California Silicon Valley, are working to develop methods to test how and how well different types of microbes survive in the extreme conditions of the atmosphere. It is still not clearly defined: (i) how long they can stay afloat in the atmosphere; (ii) how long and in what conditions airborne microbes can survive; (iii) whether our atmosphere might hold entire ecosystems of airborne microbes and, (iv) whether interactions between species in the atmosphere can allow microbes to evolve while in the air. The specialists in aerobiology and astrobiology try to answer the intriguing question whether microbes might be on Mars or another planet. More on the official website: https:// www.nasa.gov/ames/aerobiology.

\section{Aerobiological networks and societies}

The first national aerobiological network was created by O. C. Durham in USA, in 1928. Nowadays, monitoring stations exist in all continents. The European Aeroallergen Network (EAN) (more than 700 monitoring stations) started in 1988 and is the most developed (https://iaaerobiology.wordpress.com, access: March $\left.28^{\text {th }}, 2020\right)$. EAN belongs to the European Pollen Information System, together with public web portal: www. polleninfo.org. Among others the networks in Spain, Switzerland or UK belong to the most active and having the longest data series. Polish Aerobiological Network (http://aero.cm-uj.krakow.pl) including eight university monitoring stations has started in 2010, while the longest, regular observations have been performed since 1991 in Cracow (https://toksy-alergo.cm-uj.krakow.pl).

The German team, headed by Jeroen Buters, has created an inventory of the active pollen and fungal spore monitoring stations in the world, including up to 800 units, most of which are in Europe (> 500). This map shows the contact information of each station, and can be searched and displayed according to the users need (fig. 2). The current situation of pollen and fungal spores monitoring and (facilitate collaboration among

Figure 2. Worldwide Map of Pollen Monitoring Stations (https://www.zaum-online.de/pollen/pollen-monitoring-map-of-the-world.html, access: March $30^{\text {th }}, 2020$ ).

Image courtesy of Zentrum Allergie und Umwelt (ZAUM) Technische Universität und Helmholtz Zentrum München.

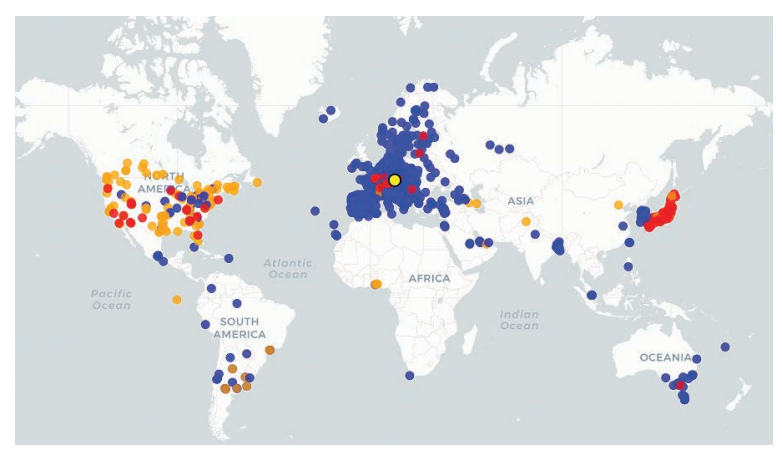


those individuals who are interested in pollen and spore counts are available) [41].

Aerobiologists and the other specialists dealing with related aspects, are associated in the scientific societies at world and regional levels. The International Association for Aerobiology (IAA) (https://iaaerobiology.wordpress.com) aim is to promote the development of aerobiology and to facilitate the international co-operation. To achieve these objectives, IAA arranges, among others, quadrennial international congresses of aerobiology, publishes newsletters at intervals and other communications for members, and cooperates with international, inter-governmental, governmental or non-governmental organisations in the field of the air quality (e.g. is affiliated with the International Union of Biological Sciences (IUBS) and the International Federation of Palynological Societies (IFPS).

The youngest and the most active regional society is the European Aerobiology Society (EAS) (www.eas -aerobiology.eu), founded in Turku during the $4^{\text {th }}$ European Symposium on Aerobiology in 2008. EAS offers a common platform to support initiatives and projects at the European level related to the field of aerobiology. Through the specific working groups, their members are dealing with quality control, education (basic courses on aerobiology), organization of European Symposia on aerobiology and legislation. One of the evident successes was to facilitate the European wide interlaboratory test focusing on setting of minimum requirements for counting airborne pollen and fungal spores $[35,42,43]$.

\section{Conclusions}

Summarising, it is worth considering some confirmed phenomena, like seasonal variability of pollen load and season length, climate changes affecting the pollen occurrence, overlapping pollen and fungal spores detected in the air, long arrange transport, to interpret the aerobiological data. Joined activity of this group of enthusiastic specialists of different interests is performed in frame of the multi centre networks and supported by the International Association for Aerobiology together with the regional societies.

\section{References}

1. Stach A, Smith M. Historia aerobiologii./History of aerobiology. In: Weryszko-Chmielewska E (ed). Aerobiologia. Wydawnictwo Akademii Rolniczej w Lublinie, Lublin 2007; 11-6.

2. Myszkowska D. Co można odkryć w powietrzu pod obiektywem mikroskopu? Alma Mater. 2011; 137-138: 22-3.
3. Emberlin J. Aerobiology, aerodynamics and pollen sampling. Adv Dermatol Allergol. 2003; 20(4): 196-9.

4. Burbach GJ, Heinzerling LM, Edenharter G et al. Pollen allergens and geographical factors. In: Akdis C, Agache I (ed). Global atlas of allergy. European Academy of Allergy and Clinical Immunology, Zurich 2014; 36-8.

5. Scheifinger H, Belmonte J, Buters $J$ et al. Monitoring, modelling and forecasting of the pollen season. In: Sofiev M, Bergmann KC (ed). Allergenic Pollen: A Review of the Production, Release, Distribution and Health Impacts. Springer Dordrecht, Heidelberg, New York, London 2013; 71-126.

6. Obtułowicz K, Myszkowska D, Stepalska D. The efficacy of symptomatic treatment of pollen allergy with regard to pollen concentration - introduction of a new coefficient. Allergy Clin Immunol. 2000; 12(3): 105-9.

7. Bousquet J, Schunemann HJ, Fonseca J et al. MACVIA-ARIA Sentinel NetworK for allergic rhinitis (MASK-rhinitis): the new generation guideline implementation. Allergy. 2015; 70: 1372-92.

8. Pfaar O, Bastl K, Berger U et al. Defining pollen exposure times for clinical trials of allergen immunotherapy for pollen induced rhinoconjunctivitis - an EAACI Position Paper. Allergy. 2017; 72: 713-22.

9. Myszkowska D. Poaceae pollen in the air depending on the thermal conditions. Int J Biometeorol. 2014; 58: 975-86.

10. Grewling E, Sikoparija B, Skjøth CA et al. Variation in Artemisia pollen seasons in Central and Eastern Europe. Agric For Meteorol. 2012; 160: 48-59.

11. Grinn-Gofron, Nowosad J, Bosiacka B et al. Airborne Alternaria and Cladosporium fungal spores in Europe: Forecasting possibilities and relationships with meteorological parameters. Sci Total Environ. 2019; 653: 938-46.

12. Myszkowska D, Majewska R. Pollen grains as allergenic environmental factors - new approach to the forecasting of the pollen concentration during the season. Ann Agric Environ Med. 2014; 21(4): 681-8.

13. Šikoparija B, Marko O, Panic M et al. How to prepare a pollen calendar for forecasting daily pollen concentrations of Ambrosia, Betula and Poaceae? Aerobiologia. 2018; 4: 203-17.

14. Kmenta M, Bastl K, Jäger $S$ et al. Development of personal pollen information-the next generation of pollen information and a step forward for hay fever sufferers. Int J Biometeorol. 2014; 58: 1721-6.

15. Akdis CA, Hellings $P W(e d)$. Global atlas of allergic rhinitis and chronic rhinosinusitis. European Academy of Allergy and Clinical Immunology. 2015.

16. Ring J, Krämer U, Schäfer T et al. Why are allergies increasing? Curr Opin Immunol. 2001; 13: 701-8.

17. EEA Report. Air quality in Europe. 2019. No 10/2019.

18. Behrendt H, Becker WM. Localization, release and bioavailability of pollen allergens: the influence of environmental factors. Curr Opin Immunol. 2001; 13: 709-15. 
19. Samolinski B, Sybilski AJ, Raciborski F et al. Prevalence of rhinitis in polish population according to the ECAP (Epidemiology of Allergic Disorders in Poland) study. Otolaryngol Pol. 2009; 63(4): 324-30.

20. Porebski G, Woźniak M, Czarnobilska E. Residential proximity to major roadways is associated with increased prevalence of allergic respiratory symptoms in children. Ann Agric Environ Med. 2014; 21(4): 760-6.

21. Chehregani A, Kouhkan F. Diesel exhaust particles and allergenicity of pollen grains of Lilium martagon. Ecotoxicol Environ Saf. 2008; 69: 568e573.

22. Lu S, Ren J, Hao X et al. Characterisation of proteins expression of Platanus pollen following exposure to gaseous pollutants and vehicle exhaust particles. Aerobiologia. 2014; 30: 281-91.

23. Schiavoni $G$, D'Amato $G$, Afferni $C$. The dangerous liaison between pollens and pollution in respiratory allergy. Ann Allergy Asthma Immunol. 2017; 118: 269e275.

24. Senechal H, Visez N, Charpin D et al. A review of the effects of major atmospheric pollutants on pollen grains, pollen content and allergenicity. The Scientific World Journal 2015; ID 940243.

25. Rogers CA, Wayne PM, Macklin EA et al. Interaction of the onset of spring and elevated atmospheric $\mathrm{CO} 2$ on ragweed (Ambrosia artemisiifolia L.) pollen production. Environ Health Perspect. 2006; 114(6): 865-9.

26. Storkey J, Stratonovitch P, Chapman DS et al. Process-Based Approach to Predicting the Effect of Climate Change on the Distribution of an Invasive Allergenic Plant in Europe. Plos One. 2014. https://doi.org/10.1371/journal.pone.008815.

27. Ziska LH, Makra L, Harry SK et al. Temperature-related changes in airborne allergenic pollen abundance and seasonality across the northern hemisphere: a retrospective data analysis. Lancet Planetary Health. 2019; 3: e124-31.

28. Ziello C, Sparks TH, Estrella $N$ et al. Changes to Airborne Pollen Counts across Europe. Plos One. 2012; 7(4): e34076.

29. Stepalska D, Myszkowska D, Leśkiewicz K et al. Co-occurrence of Artemisia and Ambrosia pollen seasons against the background of the synoptic situations in Poland. Int J Biometeorol. 2017; 61: 747-60.

30. Šikoparija B, Skjoth CA, Kübler A et al. A mechanism for long distance transport of Ambrosia pollen from the Pannonian Plain. Agric For Meteorol. 2013; 180: 112-7.

31. Grewling E, Bogawski P, Jenerowicz D et al. Mesoscale atmospheric transport of ragweed pollen allergens from infected to uninfected areas. Int J Biometeorol. 2016; 60: 1493-1500.

32. Mucci N, Gianfranceschi G, Cianfanelli $C$ et al. Can air microbiota be a novel marker for public health? A sampling model and preliminary data from different environments. Aerobiologia. 2020; 36: 71-5.

33. Albertini $R$, Colucci ME, Turchi $S$ et al. The management of air contamination control in operating theaters: the experi- ence of the Parma University Hospital (IT). Aerobiologia. 2020; 36: 119-23.

34. Myszkowska D, Kostrzon M, Dyga W et al. Bioaerosol of salt chambers in the 'Wieliczka' Salt Mine, Poland. Aerobiologia. 2019; 35: 297-311.

35. Galán $C$, Smith $M$, Thibaudon $M$ et al. Pollen monitoring: minimum requirements and reproducibility of analysis. Aerobiologia. 2014; 30(4): 385-95.

36. Oteros J, Pusch G, Weichenmeier I et al. Automatic and online pollen monitoring. Int Arch Allergy Immunol. 2015; 167: $158-66$.

37. Crouzy B, Stella M, Konzelmann Tet al. All-optical automatic pollen identification: towards an operational system. Atmos Environ. 2016; 140: 202-12.

38. Šaulinene I, Šukiene L, Daunys $G$ et al. Automatic pollen recognition with the Rapid-E particle counter: the first-level procedure, experience and next steps. Atmos Meas Tech. 2019; 12: 3435-52.

39. Buters J, Prank M, Sofiev M et al. Variation of the group 5 grass pollen allergen content of airborne pollen in relation to geographic location and time in season. J Allergy Clin Immunol. 2015; 136(1): 87-95.e6.

40. Grewling $Ł$, Bogawski P, Kostecki $Ł$ et al. Atmospheric exposure to the major Artemisia pollen allergen (Art v 1): Seasonality, impact of weather, and clinical implications. Sci Total Environ. 2020; 713: 136611 .

41. Buters J, Antunes C, Galveias A et al. Pollen and spore monitoring in the world. Clin Transl Allergy. 2018, 8: 9.

42. Galan C, Ariatti A, Bonini $M$ et al. Recommended terminology for aerobiological studies. Aerobiologia. 2017; 33: 293-5.

43. Sikoparija B, Galán C, Smith M. Pollen-monitoring: between analyst proficiency testing. Aerobiologia. 2017; 33: 191-9.

ORCID

D. Myszkowska - ID - http://orcid.org/0000-0002-1493-3990

Conflict of interests: The author declare that they have no competing interests Ethics: The contents presented in this paper are compatible with the rules the Declaration of Helsinki, EU directives and standardized requirements for medical journals. Financial support:

Copyright: (C) Medical Education sp. z 0.0. This is an Open Access article distributed under the terms of the Attribution-NonCommercial 4.0 International (CC BY-NC 4.0). License (https://creativecommons.org/licenses/by-nc/4.0/), allowing third parties to copy and redistribute the material in any medium or format and to remix, transform, and build upon the material, provided the original work is properly cited and states its license.

Corresponding author:

\section{Dorota Myszkowska, Assoc. Prof.}

Jagiellonian University Medical College, Department of Clinical and Environmental Allergology 31-503 Cracow, Botaniczna 3 phone: +48124248987 (87 98) e-mail: dorota.myszkowska@uj.edu.pl 